\title{
Influence of Highway on Regional Economy: A Case from Qingdao Yinchuan Expressway Route
}

\author{
Gao Yan ${ }^{1}$,Jiao Wenwen ${ }^{* 2}$, Chen Hongyu ${ }^{2}$ \\ ${ }^{1}$ Expressway Maintenance Department Hebei Expressway Qingyin Administration Office Shijiazhuang, China \\ ${ }^{2}$ Logistics Centre Research Institute of Highway Ministry of Transport Beijing, China
}

\begin{abstract}
In this paper, after reviewing the researches about the influence of transportation infrastructure on regional economy, it is pointed out that the influence of the transportation infrastructure on regional economy can be illustrated by network effects and spatial spillovers. A panel data model is estimated using data from Hebei economy almanac in the intervals 2007-2017. And the result shows that the interaction between economic growth and highway infrastructure is significant, and the impact of highway infrastructure on economic growth is greater. Finally, this paper suggests that the selections of variables, scopes of regions, and model dynamics can be taken into further consideration in the future.
\end{abstract}

\section{Introduction}

Transportation is not only the necessary requirement of present economy and society, but also the strong support for the sustainable development. Transportation infrastructure links enterprise productions and people's lives, facilities the resource distribution and commodity consumption, and connects rural areas with urban areas. Expressway plays a prominent role in transportation infrastructure. The emergence of expressways is a positive product of economic and social development. It not only makes people to connect more conveniently, but also promotes the development of industries and regional economics along the route.

In China, the annual increase of expressway mileage has formed a national network, which has more obvious advantages in competition with other modes of transportation in facilitating the regional flow of human and cargo. In 2019, the total mileage of highways has reached 5.0125 million kilometers, an increase of 166,000 kilometers over the previous year. And the mileage of expressways was 149,600 kilometers, ranking first in the world. Qingdao Yinchuan Expressway is a national highway running across northern China from Qingdao City in Shandong Province and Yinchuan City in Ningxia Hui Autonomous Region, with a total length of 1,610 kilometers. Hebei section of the above expressway is 181.859 kilometers, with the total investment of 4.62 billion yuan, and put into operation in the year 2005. There are 9 counties involved in the Hebei section of Qingdao Yinchuan Expressway.

This article develops a Vector Autoregressive model measurement, through which examining the linkage between transportation infrastructure and regional economic growth. And an outstanding research innovation is about the scope selection of regions, which is the 9 counties in Hebei Province along the expressway.

\section{Literature Review}

It is very important to deeply study the influence of transportation infrastructure on regional economic development, both from theoretical and empirical perspectives.

\subsection{Domestic Research}

From the view of transport corridors and economic belts, Yang Peng's research found the positive role of transportation infrastructure on regional economy. During different development periods of economic belts, transportation infrastructure functioned as the backbone, the link, the platform and the springboard [1].

The relationship between transportation infrastructure and economic growth has also been revealed by Chinese researchers. An empirical research was used to come to the conclusion that economic growth and transportation infrastructure investment presented a one-way causal relationship [2]. It was found that China's GDP and transportation infrastructure had two-way impacts [3]. A further study illustrated that a $1 \%$ increase in expressway could boost the economy by $0.034 \%$ [4].

By applying statistical methods in transportation infrastructure influence on regional economy, it was pointed out that there were significant regional differences in the eastern, central, and western China [5]. A study used provincial panel data and spatial measurement methods from 1993 to 2009 to find that the output elasticity of transportation infrastructure to regional economic growth was between 0.05 and 0.07 [6]. Some researchers believed that the increased density of transportation infrastructure

* Corresponding author: jww0821@sohu.com 
was conducive to industrial agglomeration, and helpful to realizing regional economic growth [7].

\subsection{Foreign Research}

In terms of theoretical analysis, some researchers believed that network effects and spatial spillovers were intrinsic impacts of transport infrastructure, and these two related effects worked together on regional economy [8].

The econometric methods appeared later than theoretical analysis, referring to the demonstration of the relationship between transportation infrastructure and economic growth. The first one came in the year of 1989 . A study used the panel data of some representative companies in the US to found that the construction of highways could effectively reduce the stocking inventory required by companies, thereby promoting industrial prosperity and regional economic progress [9]. Solow Growth Model was also used by some researchers, and coming to the conclusion that the transportation infrastructure had a regulatory effect on the regional economy. Other researchers used the time series to find that highway infrastructure had a significant role in promoting economic growth. Some samples were tested to show that the contribution of highways to economic growth is greater than other modes [10].

\section{Methodology}

The Vector Autoregressive (VAR) model was chosen from all various multivariate time series models to identify the relationship between economic growth and transportation infrastructure in nine counties that Qingdao Yinchuan expressway passes through, Hebei Province, China. The data was collected from Hebei economy almanac in the intervals 2007-2017, data by year. The variables in the empirical model are transformed into natural logarithms for estimation due to better calibrations, which represented by Intrans and Ingdp. The Eview 8 and excel have been chosen to assist in all process such as data processing, trimming and analyzing.

\subsection{Selection of Variables and Definition of Variables}

The variables in this study are Public Road and Street Mileage, GDP, which represent traffic network density for transportation infrastructure and economic growth respectively. The variable(s) needs to be stationary to avoid spurious regression.

Gross domestic product (GDP): GDP is the market value of all products manufactured on a territory a country over a period (usually calculated in one year). These products include the products of foreign companies and local companies including all production, service and tourism, measuring the performance of the economy and converted into comparative price This variable can be considered as the influence transportation infrastructure placed on.

Public Road and Street Mileage: A public road is any road under the jurisdiction of and maintained by a public authority (central government, province, county, town or township, local government or instrumentality thereof) and open to public travel. This variable can be identified as the factor of how economic growth.

\subsection{Research of Model}

General VAR model:

$$
\begin{aligned}
& Y_{t}=A_{t} Y_{t-1}+A_{2} Y_{t-2}+\cdots+A_{P} Y_{t-P}+s_{t}+u_{t} \\
& \text { With }
\end{aligned}
$$

$$
Y_{t}=\left[\begin{array}{c}
Y_{1 t} \\
Y_{2 t} \\
\ldots \\
Y_{m t}
\end{array}\right] ; u_{t=}\left[\begin{array}{c}
u_{1 t} \\
u_{2 t} \\
\ldots \\
u_{m t}
\end{array}\right] ; s_{t}=\left(\begin{array}{c}
s_{1 t} \\
s_{2 t} \\
\ldots \\
s_{m t}
\end{array}\right)
$$

$\operatorname{Ai}(\mathrm{i}=1,2, \ldots, \mathrm{p}):$ is the square matrix $\mathrm{m} * \mathrm{~m}$. In (1) $\mathrm{Yt}$ is the set of endogenous variables; $\mathrm{St}$ is the set of exogenous variables (if any). Let L be a latency operator, the model (1) can be written as follows:

$$
Y_{t}=\left(A_{1} L+A_{2} L^{2}+\cdots+A_{P} L^{P}\right) Y_{t}+s_{t}+u_{t}
$$

The VAR model is a combination of two models: unilabiate auto regression (AR) and simultaneous systems of equations (SEs). The VAR model combining the advantages of AR is easy to estimate using minimizing residuals (OLS) and the advantage of SEs is the estimation of multiple equations in a system. In also, the VAR model can overcome the disadvantage of SEs that it does not care about the indigenousness of economic variables. That is, macroeconomic variables are often endogenous when they interact with each other. This attribute makes the multiple regression using a regression equation much more erroneously estimated.

VAR model estimation is applied to examine the dynamic relationships between two (or more) time series variables. The model involves only predetermined variables as predictors, thus avoiding specification of endogenous dependence.

\section{Empirical analysis}

\subsection{Statistics Describing the Variables}

Table1. Statistics describing the variables in the model

\begin{tabular}{|c|c|c|}
\hline & TRANS & GDP \\
\hline Mean & 8551.474 & 118.0852 \\
\hline Median & 8478.000 & 118.2051 \\
\hline Maximum & 10052.00 & 167.5400 \\
\hline Minimum & 7481.000 & 71.96583 \\
\hline Std.Dev. & 860.6097 & 33.65455 \\
\hline Skewness & 0.350650 & 0.123542 \\
\hline Kurtosis & 1.919741 & 1.667804 \\
\hline Jarque-Bera & 0.760274 & 0.841407 \\
\hline Probability & 0.683768 & 0.656585 \\
\hline Sum & 94066.21 & 1298.937 \\
\hline Sum Sq. Dev. & 7406490 & 11326.29 \\
\hline Observations & 11 & 11 \\
\hline
\end{tabular}


Table2. Statistics describing the variables in the model (logarithm variable)

\begin{tabular}{|c|c|c|}
\hline & InTRANS & InGDP \\
\hline Mean & 9.049320 & 4.732977 \\
\hline Median & 9.045230 & 4.772422 \\
\hline Maximum & 9.215527 & 5.121222 \\
\hline Minimum & 8.920122 & 4.276191 \\
\hline Std.Dev. & 0.099598 & 0.293985 \\
\hline Skewness & 0.239340 & -0.144094 \\
\hline Kurtosis & 1.829134 & 1.656706 \\
\hline Jarque-Bera & 0.733362 & 0.865100 \\
\hline Probability & 0.693031 & 0.648852 \\
\hline Sum & 99.54252 & 52.06275 \\
\hline Sum Sq. Dev. & 0.099198 & 0.864274 \\
\hline Observations & 11 & 11 \\
\hline
\end{tabular}

\subsection{Stationarity Test of Variables}

Table3. Result of Unit Root Test

\begin{tabular}{|c|c|c|c|c|}
\hline & Intrans & Ingdp & Intrans & Ingdp \\
\hline LLC & -1.54 & 8.43 & -2.12 & -3.34 \\
\hline IPS & 1.75 & 9.32 & -3.64 & -6.78 \\
\hline ADF & 8.32 & 0.23 & 54.33 & 74.24 \\
\hline PP-Fisher & 19.65 & 0.95 & 83.64 & 153.82 \\
\hline
\end{tabular}

\subsection{VAR}

Based on the estimation results in Tab. 4, all variables used in the model have a linear correlation. This can be concluded that the VAR model may be suitable for estimating, predicting, and considering the interplay of variables through shocks. Correlation of logarithmic variables is more closely related, so the author has logarithm of variables for using the VAR model.

Table4. Result of Unit Root Test

\begin{tabular}{|c|c|c|c|c|c|c|}
\hline & Intrans & $\begin{array}{c}\mathrm{T} \\
\text { Statistic }\end{array}$ & $\begin{array}{l}\text { Standard } \\
\text { errors }\end{array}$ & Ingdp & $\begin{array}{c}\mathrm{T} \\
\text { Statistic }\end{array}$ & $\begin{array}{c}\text { Standard } \\
\text { errors }\end{array}$ \\
\hline $\begin{array}{c}\text { Intrans(- } \\
1)\end{array}$ & 0.9211 & 2.5430 & 0.3622 & 7.8890 & 2.9239 & 2.6984 \\
\hline $\begin{array}{c}\text { Intrans(- } \\
2)\end{array}$ & 0.2995 & 0.7203 & 0.4157 & -7.715 & -2.4909 & 3.0974 \\
\hline $\begin{array}{l}\text { Ingdp(- } \\
\text { 1) }\end{array}$ & $\begin{array}{c}- \\
0.0497\end{array}$ & -0.9029 & 0.0550 & 0.6473 & 1.5776 & 0.4102 \\
\hline $\begin{array}{l}\text { Ingdp(- } \\
\text { 2) }\end{array}$ & 0.0040 & 0.0883 & 0.0458 & 0.0919 & 0.2691 & 0.3415 \\
\hline C & $\begin{array}{c}- \\
1.7392\end{array}$ & -0.9982 & 1.7423 & 0.4710 & -0.0363 & 12.9793 \\
\hline
\end{tabular}

According to the VAR model, the interaction between economic growth and road traffic infrastructure is significant, and the impact of road traffic infrastructure on economic growth is greater. From the interaction between the two, the independent variables of the previous period have a positive influence on the dependent variables, while the last two periods have a negative influence. The PVAR estimated equation show as (4) and (5)

LNTRANS $=0.9 *$ LNTRANS $(-1)+0.3 *$

$\operatorname{LNTRANS}(-2)-0.05 * \operatorname{LNGDP}(-1)+0.004 *$

$\operatorname{LNGDP}(-2)-1.74$

$L N G D P=7.9 * \operatorname{LNTRANS}(-1)-7.72 *$

$\operatorname{LNTRANS}(-2)+0.65 * \operatorname{LNGDP}(-1)+0.092 *$

$\operatorname{LNGDP}(-2)-0.47$

\subsection{Impulse Responses}

To further analyze the dynamic relationship between road traffic infrastructure and economic growth, the impulse responses of them was analyzed. The result of impulse responses showed in Fig.1. The impact of road traffic infrastructure on economic growth reached its maximum at $\mathrm{t}+2$ and continued. The impact of economic growth on road traffic infrastructure reached its maximum at $\mathrm{t}+10$ and gradually declined.

Response of LNGTRANS to LNGGDP

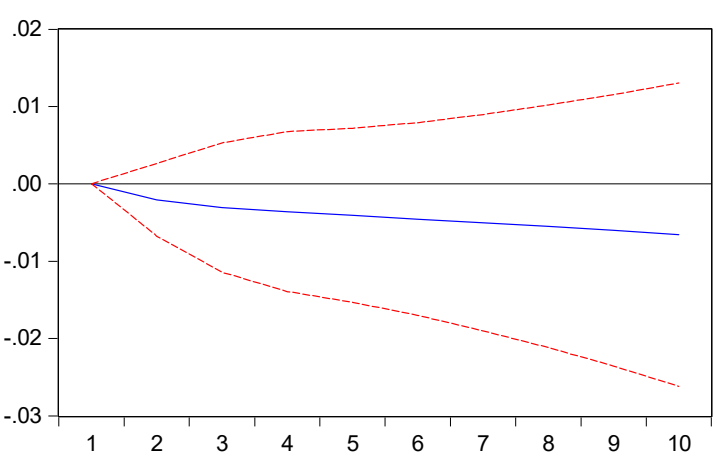

Response of LNGGDP to LNGTRANS

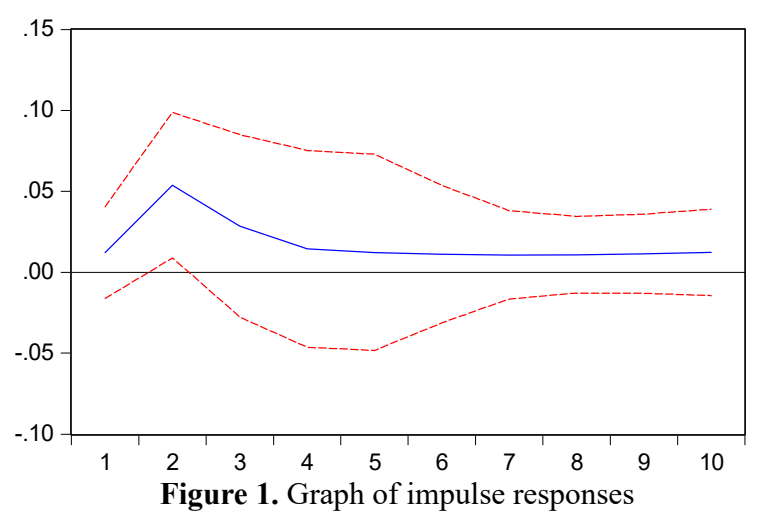

\section{Conclusion}

A panel VAR model has been implemented based on the data of highway infrastructure and economic growth in 9 counties in Hebei Province from 2007 to 2017, and observes the impulse response to characterize the relationship between economic growth and road 
infrastructure.

This article empirically demonstrates the influence of transportation infrastructure on economic development, and the result seems to explain why governments keen on infrastructure construction. Nevertheless, the author believes that there are many aspects left for future researchers. The variables data should include more transport modes but not only highway infrastructure. The scope of region could be more extensive, but not only 9 counties. And the model selection should be more dynamic.

\section{Acknowledgement}

This research was supported by Hebei Expressway Qingyin Administration Office and Research Institute of Highway Ministry of Transport. All errors and omissions are the responsibility of the authors.

\section{References}

1. P. Yang, Channel Economy. Beijing: Economic Press China, 2012.

2. B. L. Wang and Y. X. Wang, "An empirical study on the relationship between transportation infrastructure and economic growth in Liaoning Province," J. Dalian Univ. Technol, vol. 9, pp. 69-73, 2012.

3. S. F. Huang and Y. M. Wang, "Research on the relationship between China's transportation infrastructure development and economic growthbased on nonlinear granger causality test," Econ., vol. 6, pp. 28-34, 2012.

4. C. Y. Ye and X. Wang, "Transportation infrastructure, transportation industry and regional economic growth: research on spatial panel model based on provincial data," Ind. Econ. Res., vol. 2, pp. 40-47, 2013.

5. F. Zhang, "Research on the relationship between China's transportation infrastructure development and economic growth-based on nonlinear granger causality test," Wuhuan Univ. J. Humanity Soc. Sci., vol. 1, pp. 25-30, 2007.

6. X. L. Zhang, "Has transport infrastrucure promoted regional economic growth? With an analysis of the spatial spillover effects of transort infrastructure," Soc. Sci. China, vol. 3, pp. 60-78, 2012.

7. W. Wei, Q. Li, and S. J. Zhang, "Transportation infrastructure, industrial agglomeration and economic growth: empirical research based on provincial panel data," Areal Res. Dev., vol. 2, pp. 46-50, 2014.

8. A. Condecomelhorado, T. Tillema, T. D. Jong, and R. Koopal, "The role of transport infrastructure in regional economic development," J. Transp. Geogr., vol. 34, pp. 96-105, 2014.

9. C. Shirley, and C. Winston, "Firm inventory behavior and the returns from highway infrastructure investments," J. Urban Econ., vol. 55, pp. 398-415, 2004.

10. P. Melo, D. J. Grahm, and R. Brage-Ardao, "The productivity of transport infrastructure investment: a meta-analysis of empirical evidence," Reg. Sci. Urban Econ., vol. 43, pp. 695-706, 2013. 